\title{
Effects of availability of microcomputers on student and faculty research
}

\author{
DAVID M. LANE \\ Rice University, Houston, Texas
}

\begin{abstract}
The effect of the widespread availability of microcomputers on research is discussed. Student projects in a course in computer applications in psychology improved markedly, and faculty who had previously not believed that there was great value in using computers discovered innovative ways of facilitating their research.
\end{abstract}

Rice University, as part of the Apple University Consortium, has made Macintosh computers widely available on campus and has provided discounted prices to students, faculty, and staff. Over $90 \%$ of the psychology faculty have purchased their own microcomputers, and the department has over 15 microcomputers that are used for teaching and research. In this paper I will describe the impact that this availability of microcomputers has had on student and faculty research.

One immediate effect of the increased availability of microcomputers was that it enabled me to expand and improve an undergraduate course called "Computer Applications in Psychology." In this course students learn the basics of on-line experimentation, design an experiment using a computer to present the stimuli and record responses, and then run and write up the experiment. At least some programming experience is a prerequisite for this course.

Many of the students went beyond the normal course requirements and did projects that previously would not have been possible. In one project, MacPaint was used to recreate the stimuli in the Guilford-Zimmerman test of spatial ability. The student wrote a program to use a Macintosh to give the test and record response latencies and then conducted an experiment comparing different subgroups of the Rice student body. An example of the stimuli created for use in this project is shown in Figure 1. The task is to choose the clock from the second row that is in the orientation that the clock in the first row would be in after being rotated in the manner indicated. This project resulted in a professionally done adaptation of a psychometric test.

The widespread availability of microcomputers and frequent discussion of their capabilities led some faculty members who were previously skeptical about using computers in research (having seen too many people spend so much of their time programming that they did not get

Address reprint requests to the author at the Department of Psychology, Rice University, Houston, TX 77251-1892.

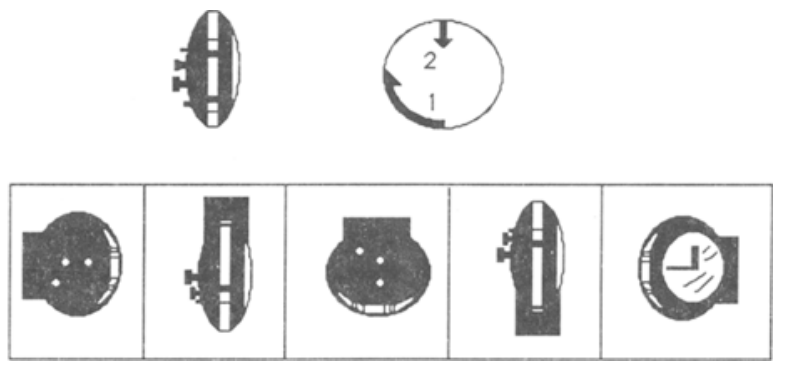

Figure 1. Example problem from spatial visualization test.

much data collected) to find ways to improve their research productivity. Of particular interest was the possibility of using the Macintosh to edit and play back digitized sound. One experiment concerned memory for auditorally presented stimuli. Normally an investigator wants to present words in different orders to different subjects, but, since speaking the words in different orders produces unacceptable variation in the way they sound, it is necessary to use some method of recording them and playing them back in different orders. Although this can be done with a tape recorder, it is a lengthy and tedious procedure. Instead, words can be digitized and stored on disk. They can then be played back under program control in any order desired. The sound editor programs for the Macintosh have also been used to prepare stimuli for other types of research, such as categorical perception.

As stated above, the availability of microcomputers had its primary effect on researchers who, sometimes with good reason, were not particularly interested in or impressed by the manner in which computers were being used in research. However, when computers are readily available and a frequent topic of conversation, even previously skeptical people discover creative ways of using computers in research. Unfortunately, computers are still quite incapable of assisting in the most important aspect of research: devising good experiments. 